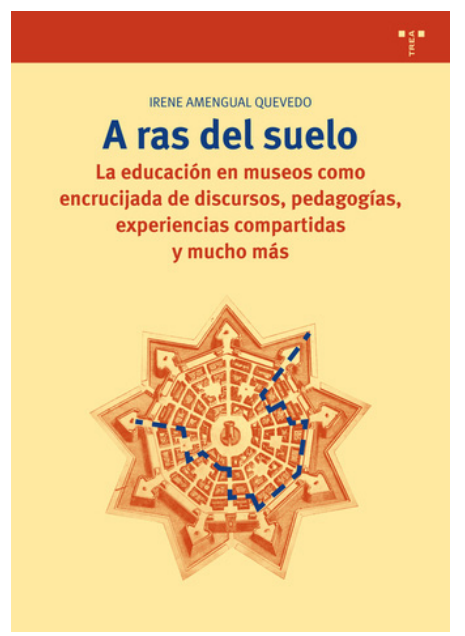

A ras del suelo. La educación en museos como encrucijada de discursos, pedagogías, experiencias compartidas y mucho más

Irene Amengual Quevedo

Año: 2015 Lugar: Gijón

Ediciones Trea

Colección Biblioteconomía y Administración Cultural

192 páginas

ISBN: 978-84-9704-892-7

\title{
La experiencia como registro hábil y efectivo para explorar la educación en museos.
}

Insiste la autora del libro en que no es posible conocer la realidad de lo que está ocurriendo en el territorio de la educación en los museos si no se vive en primera persona dicha experiencia. Y por ello resultaba muy necesario contar con este documento. Porque resulta bastante habitual que las opiniones sobre lo que pasa en las instituciones museística venga marcada por las voces de quienes analizan dichas situaciones, aunque no estén directamente implicados en ellas como observadores directos. En ese sentido, la presencia de mujeres es mayoritaria en el ámbito de la educación en museos, y por ello es importante que sean las trabajadoras mediadoras culturales quienes investiguen sobre sus propias vivencias. La experiencia de estas educadoras está trazando un riquísimo panorama bibliográfico, del que ahora podemos rememorar ejemplos tan interesantes como los trabajos de Carla Padró (a quien la autora dedica el libro) así como los de Enéritz López Martínez o los de Eva Alcaide Suárez. Tal y como sugiere Donald Schön, para permitir que las educadoras tengan más presencia institucional y cuenten con las herramientas necesarias para construir su profesión, se debería fomentar la formación de educadoras entendidas como profesionales reflexivas (Schön, 1998), cuyo desarrollo profesional no se centrase únicamente en la práctica, sino también en la reflexión y crítica respecto a su propia acción. Esto nos llevaría, como asegura Carla Padró, a ver a la educadora de arte como gestora, investigadora, facilitadora, interpretadora, una intelectual crítica. Su papel sería así el de instigadora, enredadora, provocadora de interferencias y relaciones, tal y como nos apunta Imanol Agirre.

Si bien ya resultan habituales los libros publicados en los campos de la museología, la museografía y la educación en museos, lo cierto es que la mayoría de ellos han sido escritos desde un enfoque teórico, de diseño o de planificación. Sigue existiendo un vacío en lo que respecta a documentos que aborden la construcción y la 
formación profesional de educadoras de museos desde una perspectiva experiencial y crítica. Por eso nos alegramos de que se publiquen este tipo de estudios, ya que nacen de experiencias académicas, es decir, de instancias científicas, y tras haber cumplido con su papel universitario como tesis doctorales, toman forma de manuales prácticos desde los cuales conocer realidades que permanecían ocultadas hasta ahora. Irene Amengual parte de su experiencia como educadora en Es Baluard Museo d'Art Modern i Contemporani de Palma y, en concreto, del desarrollo del programa educativo Cartografiem-nos, para revisar los planteamientos teóricos que fundamentan el ámbito museístico y educativo desde un entendimiento de las contingencias y vicisitudes que se encuentran en el terreno de la práctica y en relación con cuestiones tales como: las pedagogías radicales en contextos situados, las problemáticas del denominado giro educativo, las funciones de la educadora, o la construcción de conocimiento. Las experiencias a las que Cartografiem-nos permiten a la autora analizar su posición como educadora desde lo conflictivo y lo paradójico, dando lugar a una narrativa de la educación en museos que trasciende los discursos hegemónicos.

El libro reflexiona y comparte experiencias particulares con la esperanza de activar resonancias en el lector que le ayuden a pensar sobre su propia práctica. También visibiliza los saberes implicados en la labor de las educadoras de museos así como las complejidades imbricadas en la construcción de su conocimiento, contribuyendo así a definir la figura profesional de mediador en museos. Al reflexionar sobre su propia práctica, la autora realiza un retrato en profundidad de su profesión, utilizando para ello los programas educativos del museo en el cual ha desarrollado su labor de mediadora, como eje central desde el cual abordar las múltiples dimensiones implicadas en dicho ámbito laboral: políticas institucionales y culturales, teorías pedagógicas o construcción de conocimiento. El libro describe su experiencia trabajando dentro de los marcos de la museología crítica y de la pedagogía crítica, haciendo visibles los problemas fundamentales desde las teorías de la corriente feminista posestructuralista en educación. El volumen ofrece por tanto una mirada desde dentro del ámbito profesional y proporciona distintas perspectivas para entender la labor educativa en museos.

Este libro y la investigación en la que se basa se han generado desde el convencimiento de que la educación en museos es una profesión compleja y de que es necesario fomentar la constante formación de las educadoras de museos a partir de la reflexión sobre la práctica. Este posicionamiento, pocas veces potenciado por las instituciones culturales de nuestro país, ya hace tiempo que se viene adoptando en otros países, dentro del campo de la educación formal y de la formación de profesorado. La enseñanza es una actividad compleja que tiene lugar dentro de redes de significado social, histórico, cultural y político. A lo largo de la vida profesional, una actitud indagadora proporciona los fundamentos para operar dentro de las culturas cambiantes de las reformas escolares y los planteamientos políticos antagónicos. La indagación como posición se diferencia de la noción 
más común de indagación (en tanto que investigación en la acción o investigación docente), entendida como un proyecto limitado. Adoptar una posición indagadora significa que los docentes y los aprendices de ese oficio trabajan dentro de una comunidad para generar conocimiento local, prever su práctica y teorizar sobre ella, interpretando las conclusiones y las investigaciones de otros.

En la mayoría de ejemplos de aprendizaje profesional que se presentan en el libro, la escritura desempeña un papel crucial como herramienta para la reflexión. Algunos de los textos hacen incluso de esta una cuestión central. Aunque las iniciativas que se exploran en estos textos son distintas y presentan diferentes usos de la narrativa como herramienta para la reflexión, en estos artículos se comparte una conciencia del papel crucial que desempeña la escritura a la hora de representar y pensar la propia práctica, a la vez que como forma de reinscribir la voz del profesorado dentro de los relatos al uso sobre la enseñanza, en los que generalmente el docente «real» ha quedado silenciado. El profesional reflexivo justifica la necesidad de replantear el desarrollo profesional a partir de factores como el descrédito en el que han caído las profesiones, o la inadecuación de la formación de profesionales para el desarrollo de su profesión La insistencia de Schön por estudiar y visibilizar los procesos de aprendizaje que acontecen en el ejercicio de la práctica profesional es más que recomendable en la educación en museos, un área compuesta por profesionales que dan cuenta de iniciativas o experiencias de educación en museos, pero que pocas veces estas son abordadas de tal modo que se señalen los vínculos existentes entre la práctica y los procesos de reflexión e indagación por los cuales se cree en tanto que educadores reflexivos.

Schön sostiene que el conocimiento del profesional debe dejar de constituirse desde la racionalidad técnica (basada en el conocimiento sistemático, en el concepto de aplicación y en la separación jerárquica entre la investigación científica y la práctica de las profesiones) para desarrollarse mediante la reflexión desde la acción. Este autor defiende que son las zonas indeterminadas de la práctica (incertidumbre, singularidad y conflicto de valores), las que escapan a la racionalidad técnica, las más importantes en la práctica profesional. Cuando el profesional responde a las zonas indeterminadas de la práctica manteniendo una conversación reflexiva con los materiales de tales situaciones, rehace una parte de su mundo y con ello revela el proceso, habitualmente tácito, de construcción del universo que subyace a toda su labor (Schön, 1998: 45). Así, la reflexión sobre la práctica, en la práctica y sobre el modo como construimos nuestro saber profesional, nos hace crecer y desarrollarnos, lo que en sí constituye uno de los objetivos del libro y la investigación en la que se basa.

La naturaleza escurridiza y caótica de nuestro conocimiento profesional hace que sea difícil investigarlo, por lo cual resulta necesario poner en práctica todo tipo de recursos. Hay que combinar las herramientas analíticas del investigador con las habilidades creativas del práctico, las destrezas de observación de un naturalista con las habilidades comunicativas de un novelista. El autor describe la investigación 
en el desarrollo profesional como un campo de minas, lleno de tensiones, y al investigador como alguien completamente comprometido e implicado. El libro revisa y reformular los planteamientos teóricos que fundamentan el ámbito museístico y educativo desde un entendimiento de las contingencias y vicisitudes que se encuentran en el terreno de la práctica y en relación con las problemáticas específicas abordadas por la autora (pedagogías radicales en contextos situados, problemáticas del denominado giro educativo, funciones de la educadora, construcción de conocimiento).

Al revisar sus propias prácticas y evoluciones, Irene Amengual disecciona los trayectos por los que ha venido transitando. Nos revela situaciones vividas y no esconde los momentos menos propicios. Es lo que ocurre en el caso del capítulo titulado "De sucesos inesperados y prácticas pedagógicas residuales: explorar y conferir valor a lo que acontece en los márgenes de nuestras expectativas". Se trata de un apartado que me ha resultado especialmente atractivo, porque describe minuciosamente los pasos que sigue la investigadora para solventar aspectos no previstos. Así las cosas, conviene reconocer que tanto la positiva experiencia como educadora llevada a cabo en Es Baluard (Palma), un museo de arte actual, junto con la trayectoria investigadora marcada por la sección de Pedagogías Culturales de la Universitat de Barcelona, dan como resultado un documento especialmente valioso. Y no solamente eso. La gran ventaja de elaborar discursos desde una perspectiva crítica radica en entablar un verdadero diálogo radical con la ciudadanía (Giroux, 2005). Bienvenidas sean, por tanto, las voces que promulgan la educación como un lugar para la producción de conocimiento crítico y sujetos políticos, capaces de cuestionar y transformar las normas sociales.

\section{Referencias bibliográficas}

Giroux, H. (2005) Estudios culturales, pedagogía crítica y democracia radical. Madrid: Proa.

Schön, D. (1998) El profesional reflexivo. Cómo piensan los profesionales cuando actúan. Barcelona: Paidós. 